\title{
Taste and appetite
}

Per Møller

\begin{abstract}
In this short paper, I discuss two interpretations of the implications of food reward for healthy eating. It is often argued that foods that are palatable and provide sensory pleasure lead to overeating. I discuss an example of an experiment that claims to demonstrate this, to many people, intuitively reasonable result. I point out a number of assumptions about reward and eating behaviour underlying this sort of thinking and ask whether overeating might not instead, to a large extent, result from avoiding reward and sensory satisfaction. Four different experimental results that support the suggestion that 'quality can replace quantity' are briefly reviewed.
\end{abstract}

Keywords: Taste, Appetite, Overeating, Reward, Sensory pleasure

Humans eat foods, not nutrients. Homeostatic appetite mechanisms based on nutrients are therefore not sufficient to explain human food behaviour. Also, if homeostatic mechanisms were the only determinants of food intake, the recent problems of overeating and obesity would be hard to explain. Other control systems of ingestive behaviour and energy balance have therefore been identified [1]. These systems deal mainly with motivational, cognitive and emotional aspects of eating behaviour. Rewards derived from eating figure strongly in these extensive neural networks. Sensory pleasure from the taste of foods is therefore a major determinant of food intake.

Eating is initiated when a state of hunger is reached, but under most circumstances, not just any food will do; usually, people experience hunger for particular foods under particular circumstances.

Since foods provide reward [2], it is important to understand the processes of hedonic eating [3,4] and in particular, how these processes interact with homeostatic mechanisms controlling energy balance [1].

In this paper, I will discuss two interpretations of the implications of food reward for healthy eating.

Pleasure comes in different disguises: as the immediate sensation of wanting and liking a food when it is eaten or as a longer lasting feeling of well-being after a meal. Berridge and his coworkers have proposed a model of reward based on liking, wanting and learning [2,5]. Liking has been studied very much, despite its inability

Correspondence: pem@life.ku.dk

Department of Food Science, University of Copenhagen, Rolighedsvej 30, 1958 Frederiksberg, Denmark to predict very much of people's food behaviour [6]. Motivational processes of wanting and desire seem to change more during a meal and to be better able to predict behaviour [7]. Obviously, pleasure derived from a meal also depends on expectations prior to eating it and on bodily and mental satisfactions and well-being experienced after a meal. These are problems that are virtually untouched by scientific investigation. We need to devise new methods of quantifying pleasure and satisfaction. These methods will probably have to rely on measurements of different types of memory and on measurements of interoceptive states [8].

Optimally, the foods we eat should be perceived as appetitive, not just as filling. Will high gastronomic quality of foods consumed on a daily basis leads to overeating, thereby exacerbating problems of overweight and obesity? This view has indeed surfaced in certain scientific circles [9-11]. It might, to some, seem almost self-evident, but to others, like myself, not at all so. From highly unscientific introspection and conversations with friends and colleagues about these matters, it seems that most of us eat far less of high-quality Parmesan cheese when it is offered, than of cheap, not so tasty hard cheeses. The same applies to wines and chocolate and all other types of food. Very few people can eat a whole $100 \mathrm{~g}$ bar of Valrhona chocolate in one go but easily perform this feat with chocolate of a lesser quality. From a more epidemiological point of view, one would wonder why the obesity problem in France is less severe than in other affluent countries with foods and meals generally of a lower quality than those served in France [12]. Many scientists have argued that 
increased pleasure and variety lead to overeating. There is probably little doubt that sensory-specific satieties guide us to eat meals which contain different tastes and textures and this is one of the nature's tricks to help us eat diets balanced in macro- and micro-nutrients without needing to know anything whatsoever about nutrition science $[4,13,14]$. On the other hand, experiments with real meals under ecologically valid circumstances, as opposed to the often very artificial arrangements and foods subjects face in laboratories, suggest that 'liking' per se does not predict when a meal ends [6]. Nevertheless, many workers claim to have demonstrated that pleasure and high variety are important factors for overeating. One example of this kind of thinking is demonstrated in a recent paper by Epstein and coworkers [9].

Epstein et al. randomly assigned 16 obese and 16 non-obese women (aged 20-50 years) to receive a macaroni and cheese meal presented 5 times, either daily for 1 week or once a week for 5 weeks. They also claim to have measured 'habituation' to the food stimuli. Habituation to a stimulus is an expression of the decrement in behavioural and physiologic responses to a stimulus, often observed when repeatedly presenting the same stimulus over and over again. Habituation is an attentional effect that does not involve sensory adaptation/fatigue or motor fatigue. Epstein et al. interpret it differently, describing habituation as a form of learning. Referring to previous work by themselves and others that investigated short-term habituation in their use of the term, the question they ask in this paper is whether there is such a thing as 'long-term' habituation to food.

Whether or not any effects observed on intake are causally related to 'habituation' is interesting, but not crucial to potential applications of results like these in the design of meal schemes. The results of the experiment showed that for both obese and non-obese women, daily presentation of a bland food resulted in faster habituation and less energy intake than did once-weekly presentation of the bland food. The smaller energy intake in the once-a-day condition was not very significant and might very well have resulted from a serious design flaw of the experiment. Nevertheless, the authors conclude that, if you are offered the same (bland) meal on 5 consecutive days, you will consume less of that particular meal on day 5 than you will on the fifth encounter if you are only offered the (particular) meal once a week for 5 weeks. This result led Epstein et al. to suggest that 'reducing variety may be an important component of interventions for obesity. Habituation may provide a mechanism for the effects of variety on energy intake, such that within-session habituation during a meal can lead to reduced intakes with reduced variety of foods' [9].

This experiment was considered so important by the editors of the American Journal of Clinical Nutrition that it prompted an editorial written by Nicole M Avena and Mark S Gold [10]. Avena and Gold are fascinated by this work and write.... 'The findings of Epstein et al. provide support and guidance in developing dietary advice, such as the suggestion that people try to eat the same food each day, in which case habituation may develop that would reduce the likelihood of overeating and subsequent obesity'.

And further... 'Thus, the work of Epstein et al. is important to consider in contemplating and designing meal plans in our variety-rich environment. Clearly, schoollunch planners and public health officials should note that diversity in the menu is not necessarily a virtue, and in fact it may be associated with promoting excess food intake and increased body mass index'... In summary, it is suggested that we should 'try to eat the same food each day' and the call is out for 'school-lunch planners and public health officials' to note these results.

These writings represent one interpretation of the implications of food reward for healthy eating. It basically claims that unless we severely limit rewards obtained from eating, we run the risk that the obesity epidemic will become even worse than it already is.

Eating food when hungry is obviously rewarding. This makes evolutionary sense. Since eating is necessary for survival, the signals needed to initiate the process of eating must be strong. But it does not follow logically that because initiating signals are strong, people will continue eating beyond satiation and sensory satisfaction. The argument rests on an assumption that the desire for reward is unlimited. This might indeed be the case in certain pathological states, but that it is generally the case is an assumption. In other rewarding human activities, it is well known that 'refractory periods' are necessary to fully enjoy the activity.

As noted above, people often consume substantially less of a food that provides more sensory pleasure than they do of a blander version of the food. That is, the more sensory rewarding a food is, the less people tend to eat of it. If this is the case, sensory satisfaction could promote healthier eating rather than the opposite. I will briefly discuss four sets of data suggesting that this might actually be the case.

The question can be phrased as whether 'quality' can replace 'quantity'.

The striatum is an area in the reward circuit in the brain, which has been implicated in many types of rewarding behaviours. Dopamine is an important neurotransmitter for the functioning of the striatum. Wang and coworkers [15] used positron emission tomography (PET) to measure the availability of dopamine receptors in the striatum in obese individuals and found an inverse relationship between BMI and availability of dopamine receptors. Since dopamine modulates reward circuits, this result suggests that dopamine deficiency in obese 
individuals may perpetuate pathological eating as a means to compensate for decreased activation of these circuits. That is, eating is driven by reward and continues until enough reward has been obtained. Under the assumption that well-tasting/high sensory quality foods provide more reward per energy unit than bland foods, this result supports the hypothesis that 'quality can replace quantity'.

In an experiment on the effects of trigeminal stimulation (hot spices) on hunger and satiety, $\mathrm{HH}$ Reisfelt and I came across a result which is relevant for the present discussion [16]. The subjects in the experiment attended the laboratory twice. On one of the visits, they were served an ordinary industrially manufactured tomato soup and were asked to report on hunger and satiety feelings, as well as on liking and wanting (and other measures which are not important in this context). During the other visit, they were served the same base soup, but this time, we had spiced the soup with chili.

We found that satiety increased faster when subjects ate the soup spiced with chili. Also, wanting of more of the spiced soup decreased faster over time than wanting of the base soup, even though wanting of the spiced soup was higher initially. The faster satiation and decrease in wanting when eating the spiced soup might conceal a wish to stop eating caused by a lower appreciation of the spiced soup than of the ordinary soup. We found, however, the opposite effect. The subjects liked better the spiced soup that satiated them faster. That is, eating a more rewarding food does not imply that normal subjects will eat more of it.

In a paper entitled 'eating what you like induces a stronger decrease in wanting to eat' [17], Lemmens et al. demonstrated just that effect with a randomized crossover design. In this experiment, the subjects came to the laboratory twice. During one visit, they were served a portion of chocolate mousse and during the other visit, a portion of cottage cheese. Caloric content was the same in both servings, and the subjects' hunger feelings were the same on the two visits. Chocolate mousse was liked more than the cottage cheese. By means of an image-based method, wanting for a large number of different foods was measured before and after intake of the foods. Lemmens et al. found that wanting dropped significantly for most food categories after intake of the chocolate mousse whereas this was not the case after eating the cottage cheese, which was liked less than the chocolate mousse. This result suggests that it is not a good idea to limit intake of liked foods in order to limit overall intake, under the assumption that people will tend to eat more of a food the more they want it.

Pelchat and coworkers [18] investigated brain activity using functional magnetic resonance imaging (fMRI) in people who had eaten two different diets for 1.5 days prior to the experiment. One group ate a monotonous diet, vanilla-flavoured Boost, whereas the other group ate a normal diet. The subjects in the normal diet group were also given two cans of Boost to familiarize themselves with it. Information about favorite foods was collected from all the subjects. After the 1.5 days of eating a normal diet or a monotonous diet, the subjects were scanned while they were told to imagine the sensory properties of a number of their favorite foods as well as of the Boost. The monotonous diet group showed greater activation to the craved or liked foods than to the monotonous Boost. Craving-related activations were detected in the hippocampus, insula and caudate. These areas have previously been reported to be involved in drug craving. Interestingly, no such differences were found for the normal diet group.

This result suggests that eating a monotonous diet induces stronger food cravings of liked foods that are often energy-dense. Under most circumstances, this will lead to a larger energy intake.

A better understanding of reward-related implications for healthy eating is, of course, not sufficient to fully understand and help prevent inappropriate eating behaviour. Habit and preference formation [19-21] and especially designing schemes where children (and other people) come to appreciate foods which are low in energy content is also important as is more research into self-regulation [22,23].

Before we understand these different basic scientific problems better, scientists should probably be a little less cocky in handing out advice to political decision makers.

\section{Competing interests}

The author declares that he has no competing interests.

Received: 2 December 2014 Accepted: 2 December 2014

Published: 9 February 2015

\section{References}

1. Berthoud H, Morrison C: The brain, appetite, and obesity. Annu Rev Psychol 2008, 2008(59):55-92.

2. Berridge K: Food reward: brain substrates of wanting and liking. Neurosci Biobehav Rev 1996, 20(1):1-25.

3. Kahneman D, Diener E, Schwarz N (Eds): Well-Being: The Foundations of Hedonic Psychology. New York: Russell Sage; 1999.

4. Sørensen L, Møller P, Flint A, Martens M, Raben A: Effect of sensory perception of foods on appetite and food intake: a review of studies on humans. Int J Obesity 2003, 27:1152-1166.

5. Berridge KC, Robinson TE: Parsing reward. Trends Neurosci 2003, 26:507-513.

6. Reinbach H, Martinussen T, Møller P: Effects of hot spices on energy intake, appetite and sensory specific desires in humans. Food Quality Pref 2010, 21:655-661.

7. Olsen A, Ritz C, Hartvig D, Møller P: Comparison of sensory specific satiety and sensory specific desires to eat in children and adults. Appetite 2011, 57:6-13.

8. Craig AD: How do you feel? Interoception: the sense of the physiological condition of the body. Nat Rev Neurosci 2002, 3:655-666.

9. Epstein LH, Carr KA, Cavanaugh MD, Paluch RA, Bouton ME: Long-term habituation to food in obese and nonobese women. Am J Clin Nutr 2011, 94:371-376

10. Avena NM, Gold MS: Variety and hyperpalatability: are they promoting addictive overeating? Am J Clin Nutr 2011, 94:367-368. 
11. Møller P, Köster EP: Variety and overeating: comments on long-term habituation to food. Am J Clin Nutr 2012, 95:981.

12. Rozin P, Kabnick K, Pete E, Fischler C, Shields C: The ecology of eating: smaller portion sizes in France than in the United States help explain the French paradox. Psychol Sci 2003, 14(5):450-454.

13. Rolls BJ, Rolls ET, Rowe EA, Sweeney K: Sensory specific satiety in man. Physiol Behav 1981, 27:137-142.

14. Rolls BJ, Rowe EA, Rolls ET: How sensory properties of foods affect human feeding-behavior. Physiol Behav 1982, 29:409-417.

15. Wang GJ, Volkow ND, Logan J, Pappas NR, Wong CT, Zhu W, Netusll N, Fowler JS: Brain dopamine and obesity. Lancet 2001, 357:354-357.

16. Møller P: Gastrophysics in the brain and body. Flavour 2013, 2:8.

17. Lemmens S, Schoffelen P, Wouters L, Born J, Martens M, Rutters F, Westerterp-Plantenga M: Eating what you like induces a stronger decrease of 'wanting' to eat. Physiol Behav 2009, 98:318-325.

18. Pelchat ML, Johnson A, Chan R, Valdez V, Ragland JD: Images of desire: food-craving activation during fMRI. Neurolmage 2004, 23:1486-1493.

19. Schaal B, Marlier L, Soussignan R: Human fetuses learn odours from their pregnant mother's diet. Chem Senses 2000, 25:729-737.

20. Hausner H, Nicklaus S, Issanchou S, Mølgaard C, Møller P: Breastfeeding facilitates acceptance of a novel dietary flavour compound. Clin Nutr 2010, 29:141-148.

21. Hausner $\mathrm{H}$, Olsen A, Møller P: Mere exposure and flavour-flavour learning increase 2-3 year-old children's acceptance of a novel vegetable. Appetite 2012, 58:1152-1159.

22. de Ridder DTD, Lensvelt-Mulders G, Finkenauer C, Stok FM, Baumeister RF: Taking stock of selfcontrol: a meta-analysis of how trait self-control relates to a wide range of behaviors. Pers Soc Psychol Rev 2012, 16:76-99.

23. Hofmann W, Schmeichel BJ, Baddeley A: Executive functions and self-regulation. Trends Cogn Sci 2012, 16:174-180.

doi:10.1186/2044-7248-4-4

Cite this article as: Møller: Taste and appetite. Flavour 2015 4:4

\section{Submit your next manuscript to BioMed Central and take full advantage of:}

- Convenient online submission

- Thorough peer review

- No space constraints or color figure charges

- Immediate publication on acceptance

- Inclusion in PubMed, CAS, Scopus and Google Scholar

- Research which is freely available for redistribution 